\title{
Combined Application of 4D BIM Schedule and an Immersive Virtual Reality on a Modular Project: UNLV Solar Decathlon Case
}

\author{
Rajarshi GHIMIRE${ }^{1}$, Seungtaek LEE², Jin Ouk $\mathrm{CHOl}^{3}$, Jin-Yeol LEE ${ }^{4}$, Yong-Cheol LEE ${ }^{5}$ \\ ${ }_{1}^{1}$ Graduate Assistant, Department of Civil and Environmental Engineering and Construction, University of Nevada, Las Vegas \\ ${ }^{2}$ Postdoctoral Scholar, Department of Civil and Environmental Engineering and Construction, University of Nevada, Las Vegas \\ ${ }^{3}$ Assistant Professor, Department of Civil and Environmental Engineering and Construction, University of Nevada, Las Vegas \\ ${ }^{4}$ Master's Student, School of Architecture, University of Nevada, Las Vegas \\ ${ }^{5}$ Assistant Professor, Bert S. Turner Department of Construction Management, Louisiana State University
}

Submitted April 20, 2020

Accepted September 28, 2020

Published January 2021

\section{Corresponding Author}

Jin Ouk Choi, Ph.D

jinouk.choi@unlv.edu

\section{Department of Civil and}

Environmental Engineering and

Construction

University of Nevada, Las Vegas

4505 S. Maryland Pkwy

Las Vegas, NV 89154

\section{DOI}

http://doi.org/10.29173/ijic236

Pages 1-14

ISSN 2563-5034

Distributed under Creative

Commons CC-BY-NC-ND 4.0

\section{ABSTRACT}

The use of a 4D schedule as technological advancement has brought significant improvement to the planning and execution of construction projects, through visualizing step-wise construction progress, following a sequence of pre-planned activities, and finalizing a baseline schedule with necessary changes. Moreover, the application of immersive virtual reality (IVR) to create an interactive 4D BIM schedule of a planned structure has made it possible to create a detailed plan of any construction project. Because of these benefits, the use of $4 \mathrm{D}$ schedules and immersive virtual reality in the construction industry has increased, leading to improved planning and execution. However, past studies have given little attention to the applications of such technologies on modular projects. Thus, this research applied a 4D schedule, along with immersive virtual reality, on a modular project, and verified their benefits and effectiveness. The results showed that most of the participants who experienced a 4D BIM schedule, along with immersive virtual reality (4D/IVR), strongly agreed that it is an easy and straightforward way to visualize the project, understand the schedule, and find any errors. Moreover, while fewer than half of the participants scheduled the assembly sequence correctly with conventional schedule and 2D drawings, almost all of them sequenced the assembly successfully with 4D/IVR. Based on the findings, this research concludes that the implementation of a 4D BIM schedule, along with virtual reality technology, can enhance the fabrication and assembly performance of modules.

\section{KEYWORDS}

Off-site construction; Immersive virtual reality; 4D schedule; Solar Decathlon; Industrialized construction 


\section{Introduction}

Modularization is a construction process in which some or all of the work on a job-site is moved to fabrication shops [1]. A number of studies have addressed the advantages, difficulties, and tendencies in modularization applications [1-3]. Several studies claim that the effective modularization utilization decreases the overall cost, duration, and accidents on construction projects; reduces construction waste and noise; and improves the safety, quality, productivity, and environmental performance [15]. Despite modularization's benefits, on-site storage areas and transportation/logistics are barriers to its application [6]. These challenges necessitate effective planning and scheduling to ensure efficient transportation to and proper storage of modules at the assembly site.

Fortunately, these challenges of planning and scheduling can be overcome by effective technology use. The representative technologies are 4D building information modeling (BIM) scheduling and virtual reality (VR) [7]. BIM has led to improved understanding, higher quality, better coordination, and more efficient management through 3D visualization. Visualized 3D models show a better physical reality in construction operation simulation, providing detailed information [8]. 4D scheduling is the integration of $3 \mathrm{D}$ BIM with a construction schedule, enabling simulated visualization of a project's construction/fabrication sequence from beginning to end $[9,10]$. Construction project difficulties, such as those that arise in space and work sequence, are mitigated by the use of a 4D schedule [11]. 4D schedules have been used for improved understanding [9], project coordination [9], structural safety analysis [12], risk mitigation strategies [13], and site management [14], as well as construction planning and progress control [15].

Another useful technology is VR, which is a computergenerated interactive environment, allowing users to feel like they are in the environment itself [16]. Using VR, construction planners and designers can better perceive a building by observing the inside of the building before the start of its construction [17]. Moreover, this technology has various utilizations in the construction field, such as construction safety training [18]; high-altitude simulations, used to determine emotional and mental fatigue [19]; and in lieu of physical mock-ups, which are uneconomical [20]. VR has also been used simultaneously with different forms of BIM to attain benefits from advanced scheduling technology [17]. Advanced VR technology, such as immersive virtual reality (IVR) with VR gear, is currently available. Most previous research utilized non-immersive VR; however, IVR with a headset provides better visualization capabilities and enables more advanced human interaction with a 4D model [21].

The construction industry has benefited from using BIM and VR technologies to help in planning, design, construction, and project management [22]; workspace conflict development [7]; and construction education [23]. However, the use of these technologies has been limited in modular construction; therefore, this study evaluates its use in this area. In modular construction, most construction elements are built off-site and assembled on-site, making the assembly sequence is significantly important. According to Wang et al. [22], the assembly sequence and resource allocation can be improved by BIM and VR technologies for successful implementation and project delivery. Thus, this research applied these technologies to determine their benefits for modular construction. The case study presented is the 2020 UNLV Solar Decathlon House, which was currently under construction in Spring 2020.

\section{Literature Review}

In order to understand previous research, this section reviews the current situation of modularization, and clearly describes a 4D BIM schedule using VR.

\section{Modularization}

Modularization is a construction process in which part or all of the work is moved to a fabrication shop. Because of the significant benefits of modularization, there have been various modular construction research studies. Tatum et al. [1] studied prefabrication, preassembly, modularization, and off-site fabrication (PPMOF), with a focus on determining the driving factors, such as site access, site conditions, and contractor capabilities, which lead to the high use of PPMOF in both industrial and building construction projects. A study on prefabrication and preassembly by Haas et al. [2], to determine their impact on the construction workforce, calculated the relative weights of the drivers, advantages, impediments. They claimed that prefabrication and preassembly could reduce time, decrease supply chain duration, and lead to better productivity. Further research by Song et al. [3] verified the usefulness of PPMOF and concluded that early decision making was necessary for its successful implementation.

Later, O’Connor et al. [24] identified 21 critical success factors (CSFs) for effective modularization implementation. Similar research was done related to additional steps, termed CSFs enablers, which aid in the accomplishment of CSFs in modular construction projects [24]. Further, a study on design standardization strategies evaluated the advantages and disadvantages of combining modularization with standardization [25]. O'Connor et al. [4] studied the required changes in planning and execution from stick-built projects to modular projects, in order to achieve a higher level of modularization in the construction industry. The impact of each individual or group of modularization CSFs related to the cost and schedule success was studied by the authors [26]. Another study by Choi et al. [6] looked at the advantages and difficulties of using modularization 
in an urban environment. It identified improved quality, improved site operations, reduced durations, increased productivity, and lowered costs as the primary advantages, with on-site storage areas and logistics, and distance from the fabrication shop to job identified as difficulties for utilizing modularization.

Moreover, some studies have adopted a lean concept to modular construction. Modular construction is a hybrid of manufacturing and construction. Thus, modular construction lends itself to lean production in many ways. The aim of lean production is to improve productivity, processes, and value-adding operations, as well as reduce waste [27]. Gbadamosi et al. [28] integrated the principles of lean construction and design for manufacture and assembly to assist designers in selecting proper building materials and designing elements in a building information modeling. $\mathrm{Yu}$ et al. [29] developed a production system for the effective application of lean tools, such as standardized work and takt time planning, in building components' prefabrication. Nahmens and Ikuma [30] suggested applying a lean concept as a viable and effective strategy in modular homebuilding. In addition to this, modularization research topics have been related to a simulation model for lifting a modular house [31]; a business case analysis model [32]; innovative approaches for project standardization [33]; rapid postdisaster recovery [34]; and dimensional quality on modular construction [35]. With various modularization research, none have specifically addressed the application of 4D BIM scheduling with VR.

\section{D BIM schedule}

4D scheduling combines a construction schedule and a $3 \mathrm{D}$ model to simulate the construction process $[9,10]$. An initial study on 4D scheduling was done by Retik et al. [36], who explored the potential of using computer graphics in scheduling. Chau et al. [37] studied 4D visualization in the construction management field and concluded that it could be used for planning and managing daily activities, along with construction sites. The authors determined the usefulness of computer graphics for a construction management team. Further, Chau et al. [38] developed 4D site management model (4DSMM) software, which included site and resource management. The 4DSMM software was then used by a warehouse building in Hong Kong, and the authors found it was a good tool for communication and collaboration between construction stakeholders, namely the owner and site managers [39]. They further developed a new information system by adding a resource management system to the existing system and named it 4DSMM+ [22]. By integrating site layout management into the system, the authors' further developed software called 4D integrated site planning system (4D-ISPS), which provided more concentrated on-site planning [14]. Additionally, the usefulness of 4D CAD in each project phase, from planning to operation and maintenance, was studied by Mahalingam et al. [40], who identified its application in communicating between project stakeholders, tracking progress for contractors and subcontractors, and examining the constructability of a project by looking at conflicts. Later, $\mathrm{Hu}$ and Zhang [12] continued their previous study of 4DSMM by adding geometric information and time information to the existing system, to analyze safety during the construction phase.

3D sensing technology was combined and compared with 4D BIM for construction progress measurement [41]. Similar research was done to track construction progress, in which reliable remote sensing systems were used [42]. The authors used image-processing-based construction monitoring, whose main advantage was improved communication. A 4D schedule was also used in railway renovation in the Netherlands, where new structures (both temporary and permanent) had to be aligned with preexisting structures; this was assisted through 4D schedule and space conflict management in each phase of the project [10]. Furthermore, Olde et al. [43] added ethnographic action research to $4 \mathrm{D} \mathrm{CAD}$ in multiple project cases to support underground utility projects, which helped in conflict management while laying down new structures. In another study, Kassem et al. [44] identified and solved logistics problems, along with temporal and spatial conflicts in workspace management, using a 4D tool. In another study, 4D BIM was applied to mitigate project risks in the planning phases of a canal lock expansion project in the Netherlands [13]. Additionally, an inverse photogrammetry approach was used with 4D BIM by Braun and Borrmann [45] for automatically naming construction pictures.

Moreover, BIM and modular construction relate to process and product perspectives [46]. BIM is a good parametric modeling tool for construction practitioners, and some research has been to improve the tool. Sacks et al. [47] improved paramedic modeling for precast concrete, and Singh et al. [48] developed integrated modular coordination rules. Despite BIM's benefits in modular construction, applying current BIM is difficult and insufficient because of the difference between off-site and on-site construction processes [5, 49]. Modular construction should consider manufacturing, logistics, and assembly processes additionally [50]; and designs for manufacturing and assembly [51, 52]. Barkokebas et al. [53] tried to improve productivity in the design and manufacturing processes via BIM. Alwisy et al. [54] proposed BIM-based design automation for wood-frame manufacturing. Research by Wang and Yuan [55] and Wang et al. [56] focused on improving the assembly sequence efficiency for precast buildings by applying BIM, optimization algorithms. Although many assert that BIM benefits modular construction, some obstacles exist, such as lack of proper policy [46]. Therefore, some researchers have identified the success factors in BIM- 
enabled modular construction. For example, Li et al. [57] verified that software and project delivery are critical, and $\mathrm{Li}$ et al. [58] suggested that manufacturers and construction contractors are success factors. It is evident that BIM technology has many benefits and is widely applied in the modular construction field.

\section{Immersive Virtual Reality}

Virtual reality has also been used in the construction field because of its benefits. VR has been described as a computer-generated interactive environment, which makes users feel like being in the environment itself [16]. Woksepp and Olofsson [59] studied the usefulness and dependability of VR in construction planning and design. VR was tested on construction personnel and their direct visualization, with respondents indicating that it could be beneficial for unknown tasks. Further, they found that VR reduced misinterpretation in the planning and design phase, as it gave the planning team multiple perspectives, while increasing the overall construction process understanding. In similar research, Kasireddy et al. [63] examined and compared various VR environments for assisting virtual construction activities.

Additional research on VR was conducted by Rüppel and Schatz [17], who used virtual reality for fire evacuation with serious BIM-based game applications. As cost and space limitations are difficulties in physical mock-up building creation, VR was also used for healthcare facility design review applications [20]. Sacks et al. [18] claimed that the VR application in safety training would be more effective than conventional methods, as personnel would better remember and assess risks involved. Kim et al. [60] summarized recent studies in VR and found that lower participant numbers could be involved in VR-related research and that VR-environment realism would worsen if substandard designs were used. VR was further used to examine real-life evacuation scenarios, such as emergency situations in tunnels and hotels $[16,61,62]$.

Later, Du et al. [64] studied a means for the automatic update of BIM data to a VR model but found that the conversion of BIM data to VR is a slow process, which has restricted the use of VR in the construction industry. A paper that analyzed trends in the UK construction industry, noted that VR had been used to understand hazards in remote locations [65]. BIM and VR were also used in combination in the renovation of a shopping center in China, in order to help the workforce understand the design and construction process; it was found that this increased work efficiency and reduced design alteration and rework [66]. In another study, Feng et al. (2019) [67] used a VR environment to improve tracking accuracy, safety, and operation time in a human-excavator cooperative system. VR was also used to improve the safety performance of high-altitude environment workers by simulating their behaviors [19].
Although immersive virtual reality (IVR) has not been widely adopted, it can solve challenges in the construction field [66]. Along with 4D schedules for simulation, IVR has also been used for more realistic visualization. For example, Heydarian et al. [68] tested immersive virtual environments (IVE) and concluded that the IVE is an effective tool for design phases in architecture, engineering, and construction, to acquire end-user performance feedback. Kan and Azhar [69] investigated the feasibility of VR headsets in site planning and management, in terms of education and industry implementation perspectives, finding that VR gears were beneficial and allowed users to be immersed in a nearactual environment, as well as to gain in-depth experience pertaining to jobsite management. Despite these studies, there has been insufficient IVR applied in modular construction. Thus, the current study applied IVR in a modular construction project and evaluated the benefits and performance of IVR in modular construction.

\section{Methodology}

The goal of this study is a higher level of 4D schedule and IVR application in modular construction to enhance modular applications in the construction industry. In order to achieve this goal, this research examined the effectiveness of using a 4D schedule with IVR in modular construction. This was done in comparison to a $2 \mathrm{D}$ drawing and a project schedule, by conducting a questionnaire survey with UNLV students. This study intends to assist practitioners and educators in the modular construction industry by first examining this technology with university students. This study has the following research steps: 1) developing a 4D BIM schedule model with IVR; 2) asking students to experience the IVR; 3 ) conducting a survey and collecting the data; and, 4) analyzing the survey data.

At first, this study generated a 4D schedule and IVR model of the UNLV Solar Decathlon House using 2D drawings and a project schedule (Figure 1). Figure 2 shows the process in detail. A 3D project model was developed, which was then combined with a construction schedule (Autodesk Navisworks Manage 2020) to get a 4D schedule. However, the 4D schedule in Navisworks could not be exported to the VR model, so Autodesk Revit was used to convert the model into IVR. A phase filter in Revit was adapted to add a time dimension to the $3 \mathrm{D}$ model. In Revit, module-assembly sequencing segregation was presented with different colors, so users were aware of the model's assembly sequence. Once a useable model was developed in Revit, the next step was to transform it into an IVR model, for which the EnscapeTM plugin was used. Then participants could experience IVR. Figure 3 shows the transformation, with the left showing a module phase in Revit, and the right showing different colors for new and old modules. Oculus Rift $\mathrm{S}$ was used as the IVR headset gear to experience and test the VR (see Figure 2). 


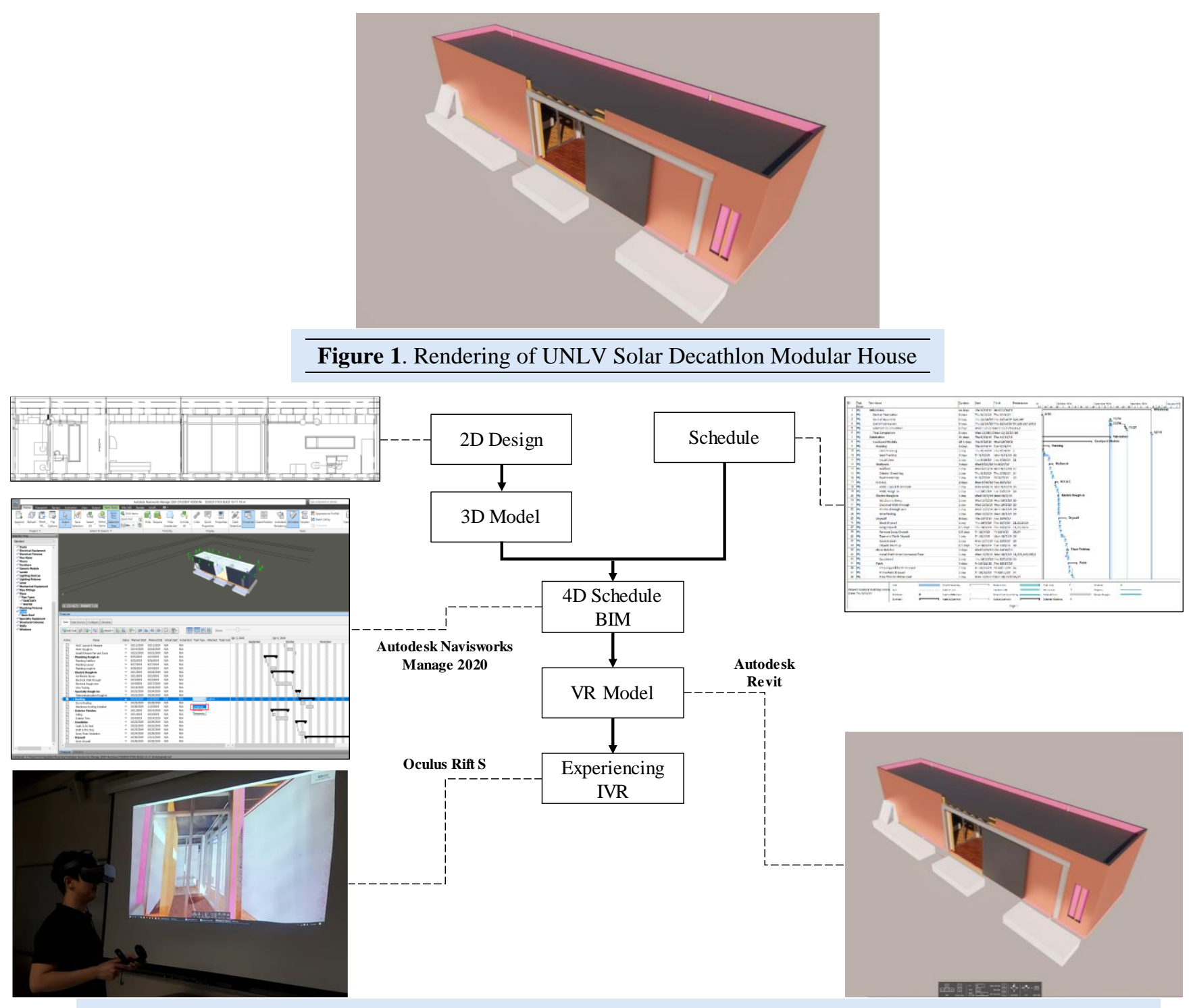

Figure 2. Developing a 4D BIM schedule model with IVR of the UNLV Solar Decathlon Modular House

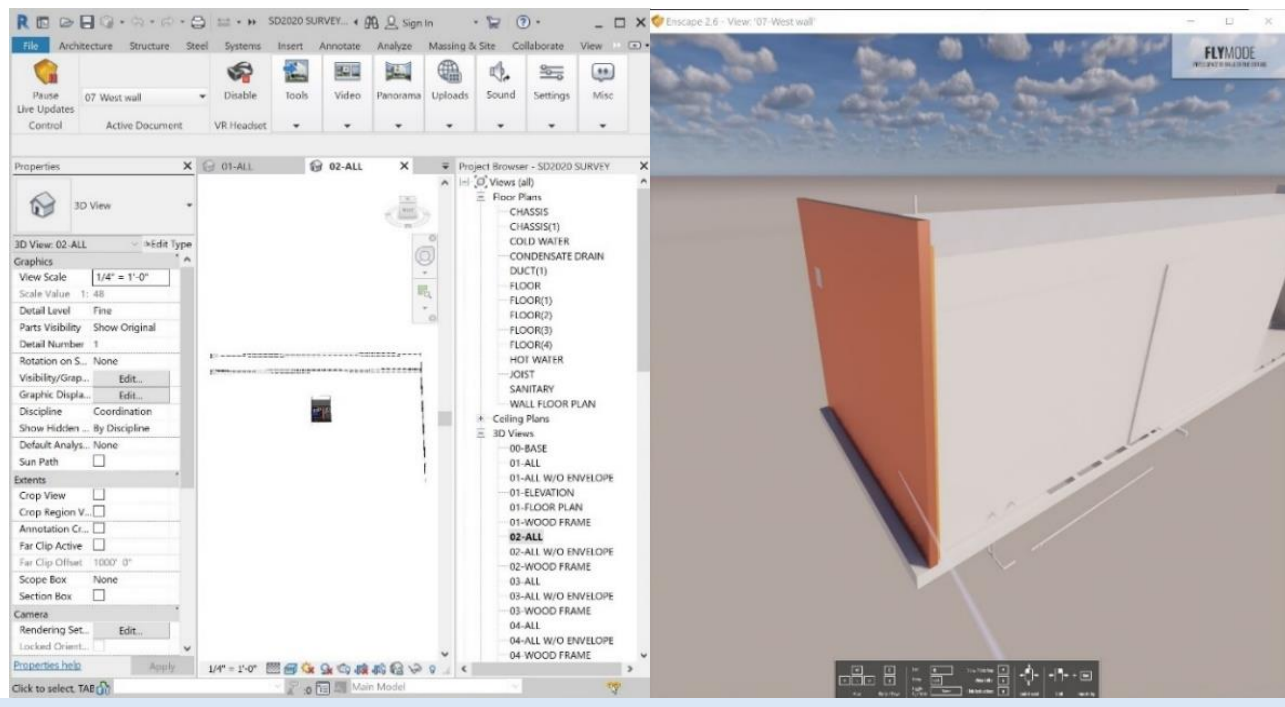

Figure 3. Transformation of a Revit model to a VR model: (left) Autodesk Revit 2020 window; (right) Enscape ${ }^{\mathrm{TM}}$ window 

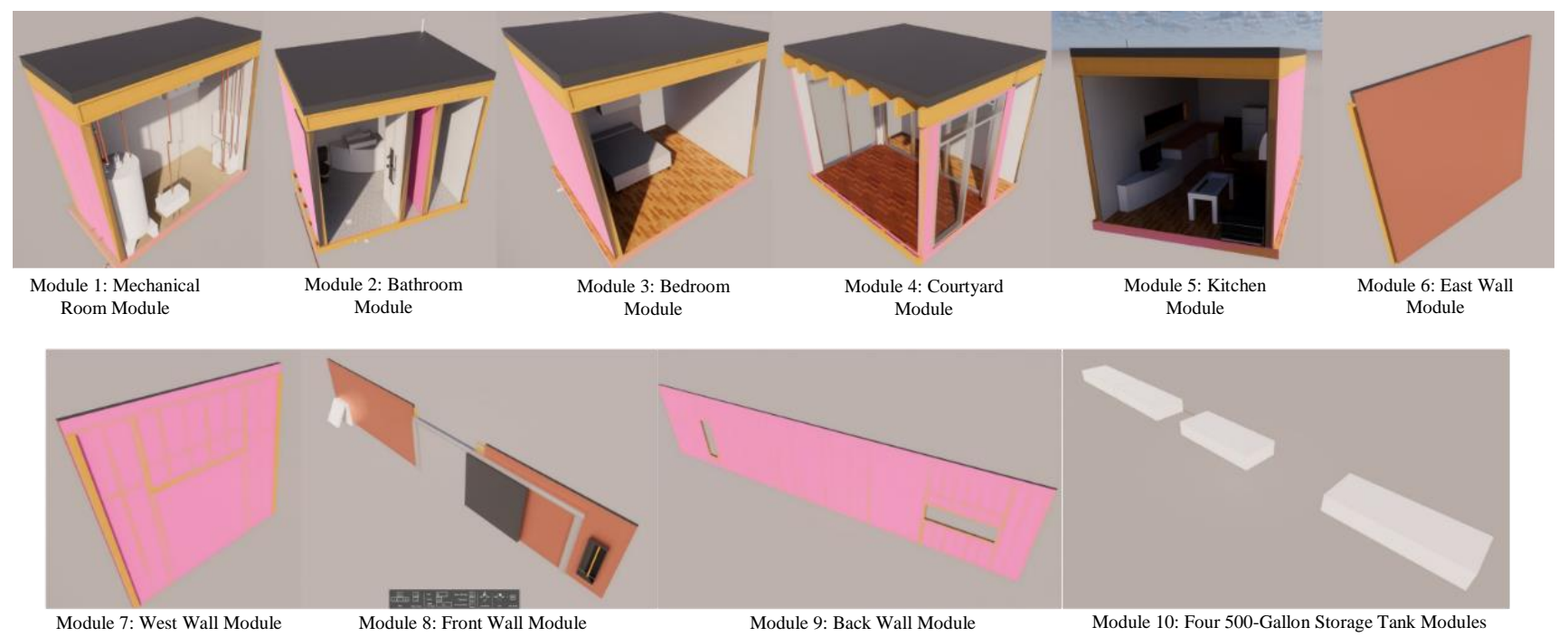

Figure 4. Ten modules of the modular house

Figure 4 shows that there were 10 modules in the VR model to show the fabrication and assembly sequence progression. The 10 modules were segregated using phases in the Revit. The test participants were shown the modules' IVR visualizations one after the other, as they were in the assembly sequence in the IVR headset. The Mechanical Room module was the first in the sequence of assembly, so it came first and was followed by the Bathroom Module. The participants were able to identify each recently added module, as it was presented in its original color, while the older modules had a whitish-grey color.

The survey questionnaire was generated so that it could examine the 2D drawing and project schedule against the $4 \mathrm{D}$ schedule and IVR model. The terminologies used in the survey were defined at the beginning and followed by a question regarding general information about the participants. After the personal information, participants were separately asked to schedule the assembly sequence of the modular house's ten modules with the help of provided 2D drawings and a project schedule. They were next asked to schedule the assembly sequence after visualization with 4D/IVR. The participants were asked to compare the $2 \mathrm{D}$ drawings and project schedules with 4D/IVR on 16 topics.

For visualization with IVR, a handout with an introduction to the Oculus Rift $S$, including how to use the IVR headset, was provided to participants to ensure they were familiar with it. After being equipped with a headset, each participant was given two minutes to acclimate to the navigation. There were three primary navigators: the thumb-stick on both controllers (left and right) and a primary index trigger on the right hand. The thumb-stick on the left-hand controller was used for horizontal plane navigation, the one on the right-hand controller was used for vertical plane navigation, and the primary index trigger controller on the right hand was used to move around the space. The user had to point to a location where they want to move, and then press the trigger for the space movement.

Finally, the survey data was digitized into a spreadsheet with Microsoft Excel 2019, then analyzed and summarized using descriptive analyses, which were conducted for all of the survey questions. In addition, this research used McNemar's test to determine the statistical significance of differences in participants' performances on module assembly sequences between traditional and 4D/IVR methods. McNemar's test determines if there are differences in a dichotomous variable between the results of two methods, rather than a continuous variable in the case of the t-test. The purpose of McNemar's test is similar to that of the paired-samples t-test, but the types of dependent variable are different.

\section{Data analysis, results, and discussions}

\section{Characteristics of Survey Participants}

To determine the effectiveness of the 4D BIM schedule with IVR, a survey was completed by the test participants. For education level, 31 participants were either undergraduate or graduate students, and none were freshmen or sophomores. Three were juniors, 13 were seniors, and 15 were graduate students. Most of the students, who participated in this study, are part-time students and have working experience as a project manager, engineer, or (at minimum) an intern. Thus, although this research collected data from university students, the results can show the effectiveness of 4D/IVR for construction industry workers. In industry experience, seven participants had less than a year, while five, seven, four, and eight had a year, two years, three years, and more than three years of industry experience, 
respectively. As for scheduling experience, 13 participants mentioned they had less than a year, 13 had a year, four had two years, and one had more than three years of experience. In the case of familiarity with modularization, only one participant was very familiar, whereas 15 participants were familiar, and 15 were not familiar with modularization. For familiarity with a $4 \mathrm{D}$ schedule and IVR, none of the participants were very familiar, six participants were familiar, and 25 participants were not familiar. In the test time taken by each participant on IVR Model visualization, the minimum time was seven minutes, the maximum was 19 minutes, and the average was about 12 minutes and 30 seconds. It was clear that participants' learning curves varied while becoming familiar with new technology. Table 1 and Figure 5 show details of the survey participants and the time taken for each during the IVR model visualization, respectively.

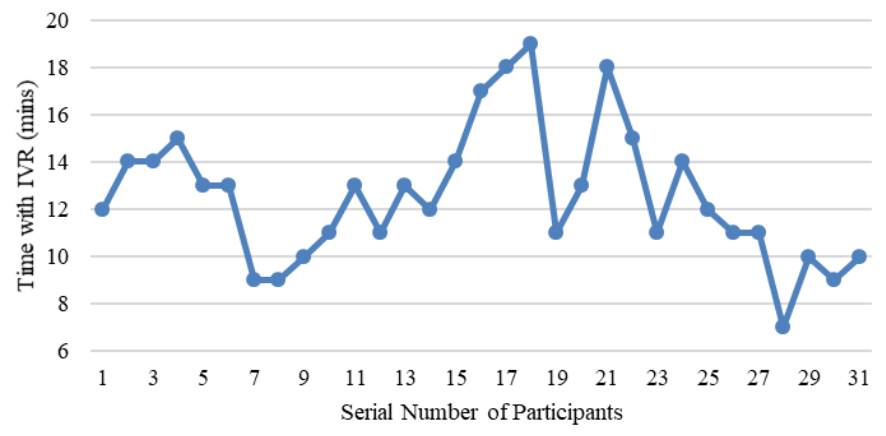

Figure 5. Time taken by each participant during IVR model visualization

Table 1. Detailed descriptions of the survey participants

\begin{tabular}{lr}
\hline Indicator & \\
\hline Education level & 3 \\
Junior & 13 \\
Seniors & 15 \\
Graduate & \\
Industry Experience & 7 \\
$\quad$ Less than 1 year & 5 \\
1 years & 7 \\
2 years & 4 \\
3 years & 8 \\
More than 3 years & \\
Scheduling Experience & 13 \\
Less than 1 year & 13 \\
1 years & 4 \\
2 years & 0 \\
3 years & 1 \\
More than 3 years & \\
Familiarity with 4D Schedule and IVR & \\
Very Familiar & 6 \\
Familiar & 6 \\
Not Familiar & 25 \\
\hline Total & $\mathbf{3 1}$ \\
\hline
\end{tabular}

Participants' performance on module assembly sequence The participants were provided 2D drawings containing a section of each module, along with a project schedule developed in MS project. Then they were asked to assemble the ten modules in the survey, using the traditional approach. The assembly sequence they created was compared to the one provided to them. Figure 6 shows the detailed results of the participants' performances. Thirteen participants completed the sequence correctly, while 18 completed it incorrectly. Conversely, when asked to do the same sequencing assembly task after visualization with 4D/IVR, which had the same assembly sequence, 24 out of 31 participants sequenced the assembly correctly. Five among the seven who had the wrong sequence assembly had just one activity sequenced incorrectly. Moreover, among the 18 participants who completed the assembly incorrectly using $2 \mathrm{D}$ drawings, 12 succeeded in assembling the sequence perfectly, and four missed only one sequence when using the 4D/IVR. In addition, this research applied McNemar's test to evaluate the statistical significance of the results. Table 2 contains a summary of the results, which proved that the participants' performances with 4D/IVR were significantly superior to their performances with the traditional approach $(\mathrm{P}=0.003)$.

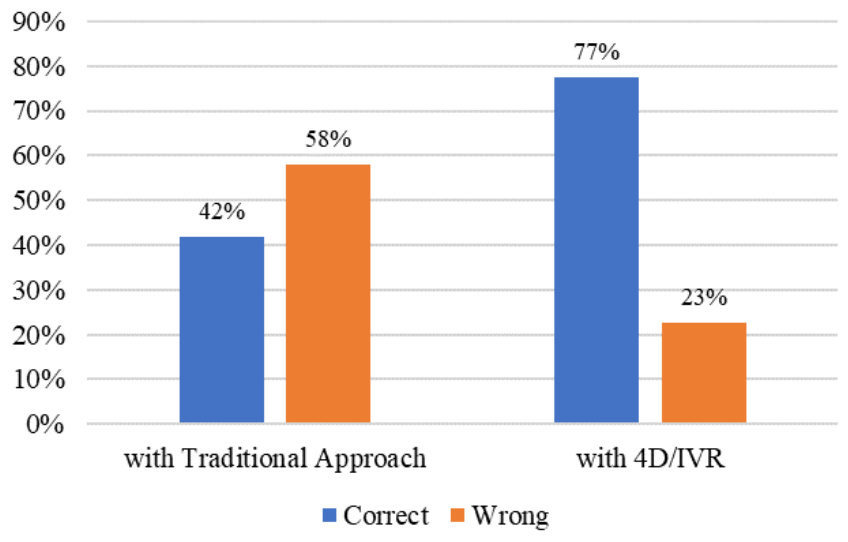

Figure 6. Assembly sequence of the modules with a traditional approach and 4D/IVR

Table 2. Results of McNemar's test

\begin{tabular}{llll}
\hline \multirow{2}{*}{$\begin{array}{l}\text { Traditional } \\
\text { Approach }\end{array}$} & 4D/IVR & \multicolumn{2}{c}{ Total } \\
\cline { 2 - 3 } & Wrong & Correct & \\
\hline Wrong & 6 & 12 & 18 \\
Correct & 1 & 12 & 13 \\
Total & 7 & 24 & 31 \\
\hline
\end{tabular}


Participants' experiences over $4 D$ schedule along with IVR

Participants were asked for their experience on five topics for 4D/IVR: 1) easy to visualize, 2) design errors, 3) easy to use, 4) felt confident, and 5) effectiveness. The responses for each topic are summarized in Table 3 below.

Table 3. Participants' responses on six topics for $4 \mathrm{D} / \mathrm{IVR}$

\begin{tabular}{lccccc}
\hline Topic & $\begin{array}{l}\text { Strongly } \\
\text { Agree }\end{array}$ & Agree & Neutral Disagree & $\begin{array}{l}\text { Strongly } \\
\text { Disagree }\end{array}$ \\
\hline $\begin{array}{l}\text { Easy to } \\
\text { visualize }\end{array}$ & $84 \%$ & $16 \%$ & $0 \%$ & $0 \%$ & $0 \%$ \\
\hline Design errors & $52 \%$ & $42 \%$ & $3 \%$ & $3 \%$ & $0 \%$ \\
\hline Easy to use & $52 \%$ & $35 \%$ & $6 \%$ & $6 \%$ & $0 \%$ \\
\hline Felt confident & $55 \%$ & $35 \%$ & $6 \%$ & $0 \%$ & $3 \%$ \\
\hline Effectiveness & $65 \%$ & $26 \%$ & $6 \%$ & $0 \%$ & $3 \%$ \\
\hline
\end{tabular}

Easy to visualize - These responses related to whether the information could be seen easily in the 4D/IVR; questions asked after participants completed the assembly sequence using the 4D/IVR. All participants agreed that the assembly was easy to visualize with the 4D/IVR; in fact, twenty-six (84\%) participants strongly agreed. It can be noted that 4D/IVR approach was easy for participants to visualize for participants, and all participants agreed that it was easier to visualize the construction plans and schedule with $4 \mathrm{D} / \mathrm{IVR}$ than with $2 \mathrm{D}$ drawings and a schedule.

Design errors-The participants were questioned to ensure that design errors could be easily located. Respondents stated that design errors were easily located using the 4D/IVR, with 16 (52\%) strongly agreeing that design errors could be easily located, 13 (43\%) agreeing, and one participant disagreeing.

Easy to use-The participants were asked if 4D/IVR was easy to use with the given materials. Sixteen (54\%) strongly agreed that the $4 \mathrm{D} / \mathrm{IVR}$ was easy to use, while 11 (35\%) agreed, and two participants disagreed.

Felt confident-The participants reported on their confidence to choose the correct information using 4D/IVR. Seventeen (55\%) strongly agreed that they felt confident using the 4D/IVR, 11 (35\%) agreed, two were neutral, and one participant strongly disagreed.

Effectiveness-The participants were questioned whether they thought construction activities could be smoothly carried out using the 4D/IVR without any mistakes. Twenty $(65 \%)$ participants strongly agreed that the 4D/IVR was effective, eight (26\%) agreed, two were neutral, and one participant strongly disagreed.

Participants' views over $4 D$ schedule along with IVR Survey data were collected from participants' responses to their views related to the $4 \mathrm{D}$ schedule and IVR. The results summarized in Tables 4, 5, and 6 were noted.
Table 4. Participants' views for $4 \mathrm{D} / \mathrm{IVR}$ and modularization

\begin{tabular}{llllll}
\hline Topic & $\begin{array}{l}\text { Strongly } \\
\text { Agree }\end{array}$ & Agree & Neutral Disagree & $\begin{array}{l}\text { Strongly } \\
\text { Disagree }\end{array}$ \\
\hline $\begin{array}{l}\text { Clearer with 4D } \\
\text { schedule and IVR to } \\
\text { understand the } \\
\text { fabrication sequence }\end{array}$ & $52 \%$ & $35 \%$ & $10 \%$ & $3 \%$ & $0 \%$ \\
\hline $\begin{array}{l}\text { Better } \\
\text { understanding of the } \\
\text { interior and exterior } \\
\text { of the fabrication } \\
\text { process with IVR }\end{array}$ & $68 \%$ & $29 \%$ & $3 \%$ & $0 \%$ & $0 \%$ \\
\hline $\begin{array}{l}\text { Assistance in } \\
\text { locating areas for } \\
\text { efficiency }\end{array}$ & & & & & \\
$\begin{array}{l}\text { improvement during } \\
\text { planning phase } \\
\text { using 4D/IVR }\end{array}$ & $45 \%$ & $45 \%$ & $6 \%$ & $0 \%$ & $3 \%$ \\
$\begin{array}{l}\text { Effectiveness of } \\
\text { 4D/IVR over } \\
\text { traditional approach } \\
\text { drawings in the } \\
\text { fabrication of the } \\
\text { modular house }\end{array}$ & $48 \%$ & $26 \%$ & $19 \%$ & $3 \%$ & $3 \%$ \\
\hline
\end{tabular}

The participants were given four statements for a response about whether the 4D/IVR increased their performance in the prefabrication process, which is a critical part of modularization. The first statement was, "It was clearer with 4D module and IVR to understand the fabrication sequence." As shown in Table 4, 16 participants (52\%) strongly agreed, and 11 participants $(35 \%)$ agreed that it was clearer to understand using the 4D/IVR. The second statement was, "IVR immersion helps in better understanding of the interior and exterior of the fabrication process." Twenty-one (68\%) of the participants strongly agreed that IVR immersion helped them with developing a better understanding of the fabrication process, nine participants $(29 \%)$ agreed, one was neutral, and none of the participants disagreed with the statement. The third statement was, "The 4D and IVR technologies assist in finding places where efficiency improvement can be made during the planning phase." Fourteen $(45 \%)$ participants strongly agreed that 4D/IVR could assist in finding efficiency improvement, 14 (45\%) agreed with the statement, two were neutral, and one participant strongly disagreed. The fourth statement was, "I found 4D schedule and IVR more effective over 2D schedules and drawings in the fabrication of the modular house." Fifteen (48\%) of the respondents strongly agreed, eight (26\%) agreed, six (19\%) were neutral, one disagreed, and one strongly disagreed that they found the 4D/IVR more effective than the traditional approach.

Approximately $87 \%$ of the participants agreed to the statements regarding whether 4D/IVR was helpful to the prefabrication process. Therefore, 4D/IVR could be utilized efficiently to understand the fabrication sequence and process, and it could be helpful for the modular 
construction workforce. IVR allowed the users to immerse themselves in a near actual environment, so they could feel like they were in the environment itself. Thus, when they assembled the module, they could get help from the IVR.

Table 5. Participants' views about $4 \mathrm{D} / \mathrm{IVR}$ vs. traditional approach

\begin{tabular}{|c|c|c|c|c|c|}
\hline Topic & $\begin{array}{l}\text { Strongly } \\
\text { Agree }\end{array}$ & Agree & Neutral & Disagree & $\begin{array}{l}\text { Strongly } \\
\text { Disagree }\end{array}$ \\
\hline $\begin{array}{l}\text { Easily locate design } \\
\text { errors while using } \\
\text { IVR than just } \\
\text { looking at 2D } \\
\text { drawings }\end{array}$ & $48 \%$ & $42 \%$ & $6 \%$ & $3 \%$ & $0 \%$ \\
\hline $\begin{array}{l}\text { Difficulties in } \\
\text { understanding the } \\
\text { traditional schedules } \\
\text { and drawings } \\
\text { without using 4D } \\
\text { and IVR }\end{array}$ & $10 \%$ & $26 \%$ & $23 \%$ & $35 \%$ & $6 \%$ \\
\hline $\begin{array}{l}\text { Confidence in using } \\
\text { 4D schedule and } \\
\text { IVR over the } \\
\text { traditional approach }\end{array}$ & $23 \%$ & $45 \%$ & $23 \%$ & $6 \%$ & $3 \%$ \\
\hline $\begin{array}{l}\text { Easier } \\
\text { communication with } \\
\text { team members and } \\
\text { stakeholders during } \\
\text { the planning phases } \\
\text { for 4D schedules and } \\
\text { traditional 2D } \\
\text { drawings }\end{array}$ & $55 \%$ & $42 \%$ & $3 \%$ & $0 \%$ & $0 \%$ \\
\hline
\end{tabular}

Next, the participants responded to four questions comparing 4D/IVR and a traditional approach. The first statement was, "I could easily locate design errors while using IVR than just looking at 2D drawings." As shown in Table 5, 15 (48\%) strongly agreed, 13 (42\%) agreed, two were neutral, and one disagreed that design errors could be more easily located with the 4D/IVR than with the traditional approach. The second statement was, "I have difficulties in understanding the traditional schedules and drawings without using 4D and IVR technologies." Three (10\%) of the respondents strongly agreed, eight (26\%) agreed, seven were neutral, 11 (35\%) disagreed, and two strongly disagreed that they had difficulties in understanding the traditional schedules and drawings without using 4D/IVR. The third statement was, "I felt more confident using of 4D schedule and IVR over the traditional approach." Seven (23\%) of the participants strongly agreed, $14(45 \%)$ agreed, seven (23\%) were neutral, two disagreed, and one strongly disagreed that they felt more confident while using the 4D/IVR than the traditional approach. The fourth statement was, "4D schedule provides easier communication with team members and stakeholders during the construction and planning phases than traditional 2D drawings." Seventeen (55\%) participants strongly agreed, 13 (42\%) agreed, and one stood neutral to the claim that $4 \mathrm{D}$ is better than $2 \mathrm{D}$ for the scope of communication. These results reflect that the participants found IVR more intuitive than the traditional approach, so they could find design errors, understand them, and communicate more easily.

Table 6. Participants' views for $4 \mathrm{D} / \mathrm{IVR}$ performance

\begin{tabular}{|c|c|c|c|c|c|}
\hline Topic & $\begin{array}{l}\text { Strongly } \\
\text { Agree }\end{array}$ & Agree & Neutral & Disagree & $\begin{array}{l}\text { Strongly } \\
\text { Disagree }\end{array}$ \\
\hline $\begin{array}{l}\text { No need to } \\
\text { contact the } \\
\text { designer for } \\
\text { design } \\
\text { information } \\
\text { after using } \\
\text { 4D schedule } \\
\text { and IVR }\end{array}$ & $23 \%$ & $32 \%$ & $23 \%$ & $19 \%$ & $3 \%$ \\
\hline $\begin{array}{l}\text { Helpfulness } \\
\text { of 4D/IVR in } \\
\text { examining } \\
\text { the schedule } \\
\text { developed }\end{array}$ & $42 \%$ & $42 \%$ & $10 \%$ & $3 \%$ & $3 \%$ \\
\hline
\end{tabular}

The participants later confirmed their views on the performance of the 4D/IVR. The first response statement related to this topic was, "I feel more knowledgeable about the details of the modules, so there is no need to contact the designer for design information after using 4D schedule and IVR." As shown in Table 6, seven (23\%) strongly agreed, $10(32 \%)$ agreed, seven $(23 \%)$ were neutral, six (19\%) disagreed, and one participant strongly disagreed that there was a lesser need to call the designer for further information with 4D/IVR than with the traditional approach. This result shows that some participants still thought that the designers were necessary when they could not find the design information. The second statement was, "The 4D and IVR were helpful for examining the schedule we developed." Thirteen (42\%) participants strongly agreed, $13(42 \%)$ agreed, and three $(10 \%)$ were neutral, while one each disagreed and strongly disagreed with the claim that they found 4D/IVR helpful in examining the developed construction schedule. The model already included the schedule information, and each module had different colors based on the module-assembly sequence. Thus, most participants could strongly agree with this statement.

\section{Conclusion}

4D schedules and IVR have been used in various trades in recent years. Their advancement in the construction industry is also notable. However, they have not been used significantly in modular projects. This study tried to overcome the rarity of $4 \mathrm{D} / \mathrm{IVR}$ use in modular projects, which was demonstrated by the unfamiliarity of most survey participants in this study. This unfamiliarity resulted in the varying amounts of time they required to manage the IVR headset to visualize the VR model. However, the participants were able to locate multiple 
design errors in the model presented to them once they were familiar with using IVR. This demonstrates that the effectiveness of IVR improves significantly when users are familiar with IVR.

During the survey, initially, the participants were provided 2D drawings and a project schedule and were asked to schedule an assembly sequence of ten modules. In the survey response, it was noted that only $42 \%$ of the participants scheduled the assembly sequence correctly. However, $96 \%$ of the participants sequenced the assembly successfully when they used 4D/IVR. Moreover, most of the participants who experienced 4D/IVR agreed that it was easy to visualize and find errors, and they stated that they felt confident using it. The majority also thought $4 \mathrm{D} / \mathrm{IVR}$ was more useful than the traditional approach and could improve the planning phase for modular construction. Lastly, most participants acknowledged that the project workers who use a $4 \mathrm{D}$ schedule and IVR might not need to contact the designer for design information and could receive help from 4D/IVR when developing the project schedule. Based on these findings, it can be concluded that $4 \mathrm{D} / \mathrm{IVR}$ is more effective than the traditional approach for modular projects when examined with experienced engineering students. However, as most of the participants were not familiar with 4D/IVR, they had difficulty handling the IVR headset. Therefore, it is important that intended users are familiar with IVR for its effective use, so it is necessary to train them for proper IVR use.

Despite the advantages of $4 \mathrm{D} / \mathrm{IVR}$, there were limitations found in this study. About half of the participants either felt dizzy, had motion sickness, or felt eye strain during the IVR model visualization session. One of the participants responded, "I got really dizzy. I find that this will be a problem for owners not used to it. It would be harder for a much bigger building." However, this issue is currently common in IVR technology, and it will soon be resolved as the technology advances. Additionally, as this paper is the first research applying 4D/IVR technology to a modular house, the one selected was simple. Thus, it is recommended to apply the 4D/IVR technology to bigger and more complex modular buildings through additional research. The possibilities for the 4D/IVR are endless, as 4D/IVR is an advanced version of the current $4 \mathrm{D} / \mathrm{VR}$ and has better visualization capabilities and better human interaction with a $4 \mathrm{D}$ model. Therefore, 4D/IVR can be applied to all 4D/VR applications, such as construction safety training, highaltitude simulations, and site management, allowing for better performance than with 4D/VR. Thus, future research should verify the feasibility of those applications and compare their performance to assure the effectiveness of $4 \mathrm{D} / \mathrm{IVR}$.

The proposed model, a 4D BIM schedule with IVR, can be applied in various phases. The main objective is for scheduling, so it can be applied in the design phase.
Besides, contractors can use 4D/IVR in the construction phase to understand design and schedule. The $4 \mathrm{D} / \mathrm{IVR}$ is also expected to help all project stakeholders communicate more easily and effectively in all phases. Through this, misinterpretations can be reduced. In addition, based on the participants' responses, 4D/IVR was found to be a useful method for presenting construction plans and designs to an owner, as it provides users with a real-world interactive experience. Moreover, with IVR, users will have a better visualization of planned structures, with a job site walkthrough even before the actual construction begins. The views expressed by the participants emphasized that the application of IVR would be valuable for understanding the conceptual design of a project and seeing its overview prior to construction.

\section{Acknowledgments}

The authors would like to thank the DESIGN+BUILD Lab at UNLV's School of Architecture and Professor Eric Weber, who prepared the 2D conceptual design of the UNLV Solar Decathlon house. We also thank the Enscape $^{\mathrm{TM}}$ team for providing the student license to the Enscape $^{\mathrm{TM}}$ plugin used in Autodesk Revit 2020 to convert the Revit model to a VR model. This research is based upon the master's thesis of Rajarshi Ghimire [70].

\section{References}

[1] Tatum, C. B., Vanegas, J. A., and Williams, J. M. (1986). Constructability improvement using prefabrication, preassembly, and modularization. Bureau of Engineering Research, University of Texas at Austin, Austin, Texas, USA.

[2] Haas, C. T., O’Connor, J. T., Tucker, R. L., Eickmann, J. A., and Fagerlund, W. R. (2000). Prefabrication and preassembly trends and effects on the construction workforce. Center for Construction Industry Studies, University of Texas at Austin, Austin.

[3] Song, J., Fagerlund, W. R., Haas, C. T., Tatum, C. B., and Vanegas, J. A. (2005). "Considering prework on industrial projects." Journal of Construction Engineering and Management, 131(6),723-733. https://doi.org/c98ck5

[4] O'Connor, J. T., O’Brien, W. J., and Choi, J. O. (2016). "Industrial project execution planning: Modularization versus stick-built." Practice Periodical on Structural Design and Construction, 21(1), 04015014. https://doi.org/fqrn

[5] Hu, R., Pan, W., and Bock, T. (2020). "Towards dynamic vertical urbanism. International Journal of Industrialized Construction, 1(1), 34-47. https://doi.org/10.29173/ijic208

[6] Choi, J. O., Chen, X. B., and Kim, T. W. (2019). "Opportunities and challenges of modular methods 
in dense urban environment." International Journal of Construction Management, 19(2), 93-105. https://doi.org/10.1080/15623599.2017.1382093

[7] Moon, H., Dawood, N., and Kang, L. (2014). "Development of workspace conflict visualization system using 4D object of work schedule." Advanced Engineering Informatics, 28(1), 50-65. https://doi.org/10.1016/j.aei.2013.12.001

[8] Kamat, V. R., and Martinez, J. C. (2001). "Visualizing simulated construction operations in 3D." Journal of Computing in Civil Engineering, 15(4), 329-337. https://doi.org/c2f4m6

[9] Kim, C., Kim, B., and Kim, H. (2013). “4D CAD model updating using image processing-based construction progress monitoring." Automation in Construction, 35, 44-52. https://doi.org/10.1016/j.autcon.2013.03.005

[10] Trebbe, M., Hartmann, T., and Dorée, A. (2015). "4D CAD models to support the coordination of construction activities between contractors." Automation in Construction, 49, 83-91. https://doi.org/10.1016/j.autcon.2014.10.002

[11] Heigermoser, D., de Soto, B. G., Abbott, E. L. S., and Chua, D. K. H. (2019). "BIM-based Last Planner System tool for improving construction project management." Automation in Construction, 104 , 246-254. https://doi.org/10.1016/j.autcon.2019.03.019

[12] Hu, Z., and Zhang, J. (2011). "BIM-and 4D-based integrated solution of analysis and management for conflicts and structural safety problems during construction: 2. Development and site trials." Automation in Construction, 20(2), 167-180. https://doi.org/10.1016/j.autcon.2010.09.014

[13] Sloot, R. N. F., Heutink, A., and Voordijk, J. T. (2019). "Assessing usefulness of 4D BIM tools in risk mitigation strategies." Automation in Construction, $106,102881$. https://doi.org/10.1016/j.autcon.2019.102881

[14] Ma, Z., Shen, Q., and Zhang, J. (2005). "Application of 4D for dynamic site layout and management of construction projects." Automation in Construction, 14(3), 369-381. https://doi.org/10.1016/j.autcon.2004.08.011

[15] Taghaddos, H., Eslami, A., Hermann, U., AbouRizk, S., and Mohamed, Y. (2019). "Auctionbased Simulation for Industrial Crane Operations." Automation in Construction, 104, 107-119. https://doi.org/10.1016/j.autcon.2019.03.015

[16] Kinateder, M., Ronchi, E., Nilsson, D., Kobes, M., Müller, M., Pauli, P., and Mühlberger, A. (2014, September). "Virtual reality for fire evacuation research." Proceedings, 2014 Federated Conference on Computer Science and Information Systems, Warsaw, Poland, Sept. 7-10, pp. 313-321. https://doi.org/10.15439/2014F94

[17] Rüppel, U., and Schatz, K. (2011). "Designing a BIM-based serious game for fire safety evacuation simulations." Advanced Engineering Informatics, 25(4), 600-611. https://doi.org/10.1016/j.aei.2011.08.001

[18] Sacks, R., Perlman, A., and Barak, R. (2013). "Construction safety training using immersive virtual reality." Construction Management and Economics, 31(9), 1005-1017. https://doi.org/10.1080/01446193.2013.828844

[19] Xing, X., Li, H., Li, J., Zhong, B., Luo, H., and Skitmore, M. (2019). "A multicomponent and neurophysiological intervention for the emotional and mental states of high-altitude construction workers." Automation in Construction, 105. https://doi.org/10.1016/j.autcon.2019.102836

[20] Kumar, S., Hedrick, M., Wiacek, C., and Messner, J. I. (2011). "Developing an experienced-based design review application for healthcare facilities using a 3D game engine." Journal of Information Technology in Construction (ITcon), 16(6), 85-104.

[21] Al-Adhami, M., Ma, L., and Wu, S. (2018). "Exploring virtual reality in construction, visualization and building performance analysis." Proceedings, 35th ISARC International Symposium on Automation and Robotics in Construction, Berlin, Germany, July 2018, pp. 969-976. https://doi.org/10.22260/ISARC2018/0135

[22] Wang, H. J., Zhang, J. P., Chau, K. W., and Anson, M. (2004). "4D dynamic management for construction planning and resource utilization." Automation in Construction, 13(5), 575-589. https://doi.org/10.1016/j.autcon.2004.04.003

[23] Wang, L. (2007). "Using 4D Modeling to advance construction visualization in engineering education." Unpublished doctoral dissertation, Penn. State University.

[24] O’Connor, J. T., O’Brien, W. J., and Choi, J. O. (2014). "Critical success factors and enablers for optimum and maximum industrial modularization." Journal of Construction Engineering and Management, $\quad$ 140(6), 04014012. https://doi.org/f54hzk

[25] O’Connor, J. T., O’Brien, W. J., and Choi, J. O. (2015). "Standardization strategy for modular industrial plants." Journal of Construction Engineering and Management, 141(9), 04015026. https://doi.org/f7n9b3 
[26] Choi, J. O., O’Connor, J. T., and Kim, T. W. (2016). "Recipes for cost and schedule successes in industrial modular projects: Qualitative comparative analysis." Journal of Construction Engineering and Management, 142(10), 04016055. https://doi.org/f85jhx

[27] Innella, F., Arashpour, M., and Bai, Y. (2019). "Lean methodologies and techniques for modular construction: Chronological and critical review." Journal of Construction Engineering and Management, $\quad$ 145(12), 04019076. https://doi.org/fqrp

[28] Gbadamosi, A. Q., Mahamadu, A. M., Oyedele, L. O., Akinade, O. O., Manu, P., Mahdjoubi, L., and Aigbavboa, C. (2019). "Off-site construction: Developing a BIM-Based optimizer for assembly." Journal of Cleaner Production, 215, 1180-1190. https://doi.org/10.1016/j.jclepro.2019.01.113

[29] Yu, H., Al-Hussein, M., Al-Jibouri, S., and Telyas, A. (2013). "Lean transformation in a modular building company: A case for implementation." Journal of Management in Engineering, 29(1), 103111. https://doi.org/10.1061/(ASCE)ME.1943$\underline{5479.0000115}$

[30] Nahmens, I., and Ikuma, L. H. (2012). "Effects of lean construction on sustainability of modular homebuilding." Journal of Architectural Engineering, 18(2), 155-163. https://doi.org/d8vz4p

[31] Khodabandelu, A., Choi, J. O., Park, J., Sanei, M. (2020). "Developing a simulation model for lifting a modular house." Proceedings, Construction Research Congress (CRC) 2020, Tempe, Arizona, USA, March 8-10, pp. 145-152 https://doi.org/10.1061/9780784482865.016

[32] Choi, J. O., O'Connor, J. T., Kwak, Y. H., and Shrestha, B. K. (2019). "Modularization business case analysis model for industrial projects." Journal of Management in Engineering, 35(3), 04019004. https://doi.org/fqrr

[33] Choi, J. O., Shrestha B.K., Shane, J., Kwak, Y.H. (2020). "Innovative technologies and management approaches for facility design standardization and modularization of capital projects." Journal of Management in Engineering, 10. https://doi.org/10.1061/(ASCE)ME.1943$\underline{5479.0000805}$

[34] Ghannad, P., Lee, Y.-C., and Choi, J. O. (2020). "Feasibility and implications of the modular construction approach for rapid post-disaster recovery." International Journal of Industrialized $\begin{array}{ll}\text { Construction, 1(1), } & \\ \text { https//doi.org/10 29173/ijic220 }\end{array}$
[35] Rausch, C., Edwards, C., and Haas, C. (2020). "Benchmarking and Improving Dimensional Quality on Modular Construction Projects-A Case Study." International Journal of Industrialized Construction, $\quad$ 1(1), 2-21. https://doi.org/10.29173/ijic212

[36] Retik, A., Warszawski, A., and Banai, A. (1990). "The use of computer graphics as a scheduling tool." Building and Environment, 25(2), 133-142. https://doi.org/10.1016/0360-1323(90)90025-M

[37] Chau, K. W., Anson, M., and Zhang, J. P. (2004). "Four-dimensional visualization of construction scheduling and site utilization." Journal of Construction Engineering and Management, 130(4), 598-606. https://doi.org/fcb4np

[38] Chau, K. W., Anson, M., and Zhang, J. P. (2005). "4D dynamic construction management and visualization software: 1. Development." Automation in Construction, 14(4), 512-524. https://doi.org/10.1016/j.autcon.2004.11.002

[39] Chau, K. W., Anson, M., and De Saram, D. D. (2005). "4D dynamic construction management and visualization software: 2. Site trial." Automation in Construction, 14(4), 525-536. https://doi.org/10.1016/j.autcon.2004.11.005

[40] Mahalingam, A., Kashyap, R., and Mahajan, C. (2010). "An evaluation of the applicability of 4D CAD on construction projects." Automation in Construction, 19(2), 148-159. https://doi.org/10.1016/j.autcon.2009.11.015

[41] Turkan, Y., Bosche, F., Haas, C. T., and Haas, R. (2012). "Automated progress tracking using 4D schedule and 3D sensing technologies." Automation in Construction, 22, 414-421. https://doi.org/10.1016/j.autcon.2011.10.003

[42] Kim, C., Son, H., and Kim, C. (2013). “Automated construction progress measurement using a 4D building information model and 3D data." Automation in Construction, 31, 75-82. https://doi.org/10.1016/j.autcon.2012.11.041

[43] olde Scholtenhuis, L. L., Hartmann, T., and Dorée, A. G. (2016). "4D CAD based method for supporting coordination of urban subsurface utility projects." Automation in Construction, 62, 66-77. https://doi.org/10.1016/j.autcon.2015.10.013

[44] Kassem, M., Dawood, N., and Chavada, R. (2015). "Construction workspace management within an Industry Foundation Class-Compliant 4D tool." Automation in Construction, 52, 42-58. https://doi.org/10.1016/j.autcon.2015.02.008 
[45] Braun, A., and Borrmann, A. (2019). "Combining inverse photogrammetry and BIM for automated labeling of construction site images for machine learning." Automation in Construction, 106, 102879.

https://doi.org/10.1016/j.autcon.2019.102879

[46] Yin, X., Liu, H., Chen, Y., and Al-Hussein, M. (2019). "Building information modelling for offsite construction: review and future directions." Automation in Construction, 101, 72-91. https://doi.org/10.1016/j.autcon.2019.01.010

[47] Sacks, R., Eastman, C. M., Lee, G., and Orndorff, D. (2005). "A target benchmark of the impact of three-dimensional parametric modeling in precast construction.” PCI Journal, 50(4), 126.

[48] Singh, M. M., Sawhney, A., and Borrmann, A. (2019). "Integrating rules of modular coordination to improve model authoring in BIM." International Journal of Construction Management, 19(1), 15-31. https://doi.org/10.1080/15623599.2017.1358077

[49] Collins, J. (2016). "Incorporating BIM into Architectural Precast Concrete Fabrication." Proceedings, $33^{\text {rd }}$ International Symposium on Automation and Robotics in Construction, ISARC, Auburn, USA, July 18-21, pp. 392-402. https://doi.org/10.22260/ISARC2016/0048

[50] Mao, C., Xie, F., Hou, L., Wu, P., Wang, J., and Wang, X. (2016). "Cost analysis for sustainable offsite construction based on a multiple-case study in China." Habitat International, 57, 215-222. https://doi.org/10.1016/j.habitatint.2016.08.002

[51] Sharma, S., Sawhney, A., and Arif, M. (2017). "Parametric modelling for designing offsite construction." Procedia Engineering, 196, 11141121. https://doi.org/10.1016/j.proeng.2017.08.069

[52] Yuan, Z., Sun, C., and Wang, Y. (2018). "Design for Manufacture and Assembly-oriented parametric design of prefabricated buildings." Automation in Construction, $88, \quad 13-22$. https://doi.org/10.1016/j.autcon.2017.12.021

[53] Barkokebas, B., Zhang, Y., Ritter, C., and AlHussein, M. (2017). "Building information modelling and simulation integration for modular construction manufacturing performance improvement." Proceedings, European Modelling and Simulation Symposium, pp. 409-415.

[54] Alwisy, A., Bu Hamdan, S., Barkokebas, B., Bouferguene, A., and Al-Hussein, M. (2019). "A BIM-based automation of design and drafting for manufacturing of wood panels for modular residential buildings." International Journal of Construction Management, 19(3), 187-205. https://doi.org/10.1080/15623599.2017.1411458
[55] Wang, Y., and Yuan, Z. (2017). "Research on BIMbased assembly sequence planning of prefabricated buildings." Proceedings, International Conference on Construction and Real Estate Management, (ICCREM 2017), Guangzhou, China, November $10-12$, pp. 10-17. https://doi.org/10.1061/9780784481059.002

[56] Wang, Y., Yuan, Z., and Sun, C. (2018). "Research on assembly sequence planning and optimization of precast concrete buildings." Journal of Civil Engineering and Management, 24(2), 106-115. https://doi.org/10.3846/jcem.2018.458

[57] Li, X., Wu, P., Shen, G. Q., Wang, X., and Teng, Y. (2017). "Mapping the knowledge domains of Building Information Modeling (BIM): A bibliometric approach." Automation in Construction, $\quad 84, \quad$ 195-206. https://doi.org/10.1016/j.autcon.2017.09.011

[58] Li, X., Li, Z., and Wu, G. (2017). "Modular and offsite construction of piping: Current barriers and route." Applied Sciences, 7(6), 547. https://doi.org/10.3390/app7060547

[59] Woksepp, S., and Olofsson, T. (2008). "Credibility and applicability of virtual reality models in design and construction." Advanced Engineering Informatics, $\quad 22(4), \quad 520-528$. https://doi.org/10.1016/j.aei.2008.06.007

[60] Kim, M., Wang, X., Love, P., Li, H., and Kang, S. C. (2013). "Virtual reality for the built environment: a critical review of recent advances." Journal of Information Technology in Construction, 18(2013), 279-305.

[61] Marsh, K. L., Wilkie, C. T., Luh, P. B., Zhang, Z., Gifford, T., and Olderman, N. (2014). "Crowd guidance in building emergencies: Using virtual reality experiments to confirm macroscopic mathematical modeling of psychological variables." Proceedings, Pedestrian and Evacuation Dynamics 2012, pp. 197-212. https://doi.org/fqt4

[62] Kobes, M., Helsloot, I., de Vries, B., and Post, J. (2010). "Exit choice, (pre-)movement time and (pre-)evacuation behaviour in hotel fire evacuation-Behavioural analysis and validation of the use of serious gaming in experimental research." Procedia Engineering, 3, 37-51. https://doi.org/10.1016/j.proeng.2010.07.006

[63] Kasireddy, V., Zou, Z., Akinci, B., and Rosenberry, J. (2016). "Evaluation and comparison of different virtual reality environments towards supporting tasks done on a virtual construction site." Proceedings, Construction Research Congress 2016, San Juan, Puerto Rico, May 31-June 2, pp. 2371-2381.

https://doi.org/10.1061/9780784479827.236 
[64] Du, J., Zou, Z., Shi, Y., and Zhao, D. (2018). “Zero latency: Real-time synchronization of BIM data in virtual reality for collaborative decision-making." Automation in Construction, 85, 51-64. https://doi.org/10.1016/j.autcon.2017.10.009

[65] Woodhead, R., Stephenson, P., and Morrey, D. (2018). "Digital construction: From point solutions to IoT ecosystem." Automation in Construction, 93, 35-46.

https://doi.org/10.1016/j.autcon.2018.05.004

[66] Ding, Z., Liu, S., Liao, L., and Zhang, L. (2019). “A digital construction framework integrating building information modeling and reverse engineering technologies for renovation projects." Automation in Construction, 102, 45-58. https://doi.org/10.1016/j.autcon.2019.02.012

[67] Feng, H., Yin, C., Li, R., Ma, W., Yu, H., Cao, D., and Zhou, J. (2019). "Flexible virtual fixtures for human-excavator cooperative system." Automation in Construction, 106, 102897. https://doi.org/10.1016/j.autcon.2019.102897

[68] Heydarian, A., Carneiro, J. P., Gerber, D., BecerikGerber, B., Hayes, T., and Wood, W. (2015). "Immersive virtual environments versus physical built environments: A benchmarking study for building design and user-built environment explorations." Automation in Construction, 54, 116126. https://doi.org/10.1016/j.autcon.2015.03.020

[69] Kan, C., and Azhar, S. (2016). "Virtual Reality Headsets for Immersive 3D Environment: Investigating Applications in Construction Jobsite Organization." Proceedings, $20^{\text {th }}$ CIB World Building Congress-Intelligent Built Environment, Tampere, Finland.

[70] Ghimire, R. (2019). "Examining the effectiveness of $4 \mathrm{D}$ schedule and virtual reality model on a modular project: UNLV Solar Decathlon Case." Master's Thesis, University of Nevada, Las Vegas. 